\title{
FAMÍLIA E NOMEAÇÃO NA CONTEMPORANEIDADE: UMA REFLEXÃO PSICANALÍTICA
}

\author{
Brunella Carla Rodriguez
}

Universidade de São Paulo

Isabel Cristina Gomes

Universidade de São Paulo

\author{
Danielly Passos de Oliveira \\ Universidade de São Paulo
}

\begin{abstract}
Resumo
O artigo pretende realizar uma reflexão acerca das novas formas de família na contemporaneidade e as possibilidades de nomeação destas, examinando as transformações de ordem simbólica nos sistemas de nomeação, filiação e relação entre os sexos. Tomando-se como base as teorias de Butler acerca das questões de gênero aliadas ao referencial psicanalítico vincular, põem-se em discussão os pontos de ruptura da norma, os momentos em que o ininteligível exige um nome para si, como uma afirmação da legitimidade da própria existência dos sujeitos. Por meio da análise de uma entrevista, com uma família homoparental masculina por adoção, são levantadas questões acerca dos lugares ocupados na família, do sistema de nomeação desta e de suas implicações vinculares, como efeito da ruptura da norma heterocêntrica. Tem-se assim a explicitação dos efeitos das reinvenções de gênero atrelados ao reconhecimento da alteridade dos sujeitos na relação conjugal e parental. Palavras-chave: família; homossexualidade; relações de gênero; psicanálise.
\end{abstract}

\section{FAMILY AND NAMING IN CONTEMPORANEITY: A PSYCHOANALYTIC REFLECTION}

\begin{abstract}
This paper intends to reflect on current family models and the possibilities to name these, examining the transformation of the symbolic order in naming systems, parenthood and relationship between sexes. Based on Butler's theories of gender issues and on psychoanalytic references for the bonds, we point out where the norm is ruptured, the moments in which the unintelligible requires a name: as an affirmation of the legitimacy of the very existence of the subject. Through the analisys of an interview, with a homoparental family by adoption, we will present questions about the roles in the family, the related naming system and its implications for the bonds, as the effect of breaking the heterocentric norm. We will make explicit the effects of gender reinventions linked to the recognition of the otherness of the subjects in marital and parental relationships.
\end{abstract}

Keywords: family; homosexuality; gender relations; psychoanalysis.

\section{FAMILIA Y NOMBRAMIENTO EN LA CONTEMPORANEIDAD: UNA REFLEXIÓN PSICOANALÍTICA}

\section{Resumen}

Este artículo pretiende realizar una reflexión acerca de las nuevas formas de familia en la contemporaneidad y las posibilidades de nombramiento de esta, examinando las transformaciones de orden simbólica en los sistemas de nombramiento, filiación y relación entre los sexos. Tomando como base las teorías de Butler acerca de las cuestiones de género aliadas al referencial psicoanálitico vincular, apuntaremos los puntos de ruptura de la norma, los momentos en que el ininteligible exige un nombre para si: una afirmación de la legitimidad de la propia existencia de los sujetos. A través de la entrevista con una familia homoparental por adopción presentaremos 
cuestiones acerca de los lugares ocupados en la familia, del sistema de nombramiento de esta y de sus implicaciones vinculares, como efecto de la norma - heterocéntrica. Explicitaremos los efectos de las reinvenciones de género atrelados al reconocimiento de la alteridad de los sujetos en la relación conyugal y parental.

Palabras clave: familia; homosexualidad; relaciones de género; psicoanálisis.

\section{INTRODUÇÃO}

A família, em sua configuração nuclear formada pelo pai, a mãe e os filhos vivendo juntos no mesmo espaço e obedecendo a uma rígida divisão dos papéis masculinos e femininos, é um fenômeno recente na história da humanidade. É fruto de importantes transformações que ocorreram com o advento da industrialização, na segunda metade do século XVIII na Inglaterra. Seu formato adveio de uma necessidade política de constituição de um espaço privado separado do espaço público. Desde então, a família foi incumbida da tarefa de assegurar a ordem social burguesa e de promover a formação das crianças em futuros cidadãos e trabalhadores. A partir do modelo nuclear heteronormativo, a família foi erigida como a matriz de identidade na constituição dos sujeitos (Arán, 2003).

Esse modelo familiar, embora tenha subsistido ao longo do tempo, tem passado por mudanças de grande importância nas últimas décadas, que assinalam a passagem da família tradicional-patriarcal à família pluralcontemporânea. Essa nova família vem se configurando paralelamente a um intenso processo de transformações nas relações entre os sexos, os gêneros e as identificações, além de um novo agenciamento das funções de mãe e pai (Tort, 2001).

Alguns autores (Borges \& Coutinho, 2008; Roudinesco, 2003) consideram a flexibilidade dinâmica e estrutural, acompanhada da perda do sentido da tradição, um momento de crise na instituição família. O abalo nas estruturas dos sistemas simbólicos - a nomeação, a filiação, a maternidade e paternidade e a identidade sexuada - abre espaço para o aparecimento de novos dispositivos relacionais e que remetem diretamente à teoria da sexualidade e do gênero, além daquelas que tratam de uma nova conceituação teórica, como é o caso da psicanálise interpsíquica ou vincular. Esta parte da concepção de que o psiquismo é um sistema aberto em continuidade-descontinuidade com os outros. Diferentemente da perspectiva intrapsíquica, a psicanálise vincular tem como conceitos base o vínculo (Spivacow, 2012; Kaës, 2011; Eiguer, 2010; Benghozi, 2010; Puget \& Berenstein, 1993) e as alianças inconscientes, dentre outros, possibilitando uma nova construção metapsicológica. A escolha pela psicanálise vincular nesta reflexão acerca da família deve-se à abertura que a mesma promove ao tratar dos vínculos intersubjetivos, possibilitando a compreensão dos novos arranjos familiares e relacionais como legítimas formas de vinculação.

Num projeto de reformulação do significado da palavra família (para compor a nova edição do dicionário Houaiss de 2016), foram coletadas opiniões 
atuais acerca da definição mais apropriada para o termo. Como resultado obteve-se que, "família: é o núcleo social de pessoas unidas por laços afetivos, que geralmente compartilham o mesmo espaço e mantém entre si uma relação solidária". Tal definição mostra-se mais completa que a anterior: "família é um grupo de pessoas vivendo sob o mesmo teto (O pai, a mãe e os filhos)" (Dicionário Houaiss, 2016). O que revela que as transformações relacionais e vinculares que estão ocorrendo na contemporaneidade não são, no entanto, acompanhadas na mesma velocidade por uma alteração das representações sociais, concebidas por Bourdieu (2005) como "realidades sociais", ou "ficções sociais". Isso gera um descompasso entre as vivências que, de um lado, podem ser bastante diversificadas, sujeitas a muitas mudanças e as representações que, de outro, podem ser enrijecidas e cristalizadas, incapazes de abranger a multiplicidade dos acontecimentos contemporâneos.

Apesar do aparecimento crescente de novos arranjos familiares nos dias de hoje, permanece no imaginário social1 um modelo de família regido pela heteronormatividade2. A ampliação do conceito de família e suas múltiplas possibilidades resultam na dificuldade de se abstrair um sentido único à mesma. Os lugares masculinos e femininos na família não mais coincidem com os ocupados pelos homens e pelas mulheres; eles circulam e com mais intensidade (Amazonas \& Braga, 2006) instigando-nos a repensar algumas fórmulas acerca da norma e do gênero.

Levando-se em conta todas as mudanças que tem ocorrido, a busca pela preservação da família como uma instituição natural, a-histórica e sagrada, parece ainda perdurar, mesmo se tornando a família nuclear cada vez mais uma experiência minoritária (Uziel, 2007). Juntamente com os avanços da tecnologia e as novas legislações, o questionamento dessa ordem simbólica tem gerado controvérsias acerca do conceito família, resultando em uma batalha política e psicanalítica que nos interpela a um posicionamento.

A funcionalidade da instituição familiar tem sido questionada (Almeida, 2012; Arán, 2003) na sociedade contemporânea, o que nos impele a refletir sobre sua viabilidade como instância de proteção e de apoio emocional para seus membros. Diante das rupturas e dos deslocamentos nas relações de sexo e

\footnotetext{
${ }^{1}$ Em enquete pela Câmara de deputados, acompanhando o Projeto de Lei 6583/13, que cria o Estatuto da Família. "Você concorda com a definição de família como núcleo formado a partir da união entre homem e mulher, prevista no projeto que cria o Estatuto da Família?". A enquete foi criada em fevereiro de 2014, para a qual $48 \%$ dos participantes responderam: sim. Câmara dos Deputados (2014). Enquete: Você concorda com a definição de família a partir da união entre homem e mulher, prevista no projeto que cria o Estatuto da Familia?. Brasília, DF: Autor. Recuperado em 06 de fevereiro de 2016, de http://www2.camara.leg.br/enquetes/votarEnquete/enquete/101CE64E-8EC3-436C-BB4A457EBC94DF4E

${ }^{2}$ Heteronormatividade é um termo que designa a grade de inteligibilidade cultural que compreende o discurso hegemônico sobre o que se entende natural do gênero, da forma de se relacionar afetiva e sexualmente e da forma de constituir família, que tem como pano de fundo a heterossexualidade como premissa obrigatória do ser. Em resumo, é um padrão de sexualidade que regula o modo como a sociedade ocidental está organizada (Petry \& Meyer, 2011).
} 
gênero, a família não pode mais ser considerada a única base para a construção identitária. Podemos pensar a família como um espaço relacional, mais do que como uma instituição, na qual se verifica uma demanda, explícita ou não, de autonomia pessoal (Rios, 2012).

\section{A FAMÍLIA, A NORMA E O GÊNERO}

A supervalorização da manutenção da família como instituição organizadora na sociedade contemporânea é a imposição de uma ordem moral face às transformações das formas de reprodução social. O discurso atual, ilustrado pela enquete acerca do conceito de família e a importância da preservação de seu modelo tradicional, pode ser violento e discriminatório, vindo a confirmar a tese de que a família, assim como outras instituições socializadoras (tais como: a escola e a igreja), tende a permanecer no modelo heterocêntrico, ou seja; caracteriza-se como relativamente estável, de transformação lenta (Horkheimer, 2003).

Apesar da dificuldade de constituir identidade e família fora da norma heterocêntrica, as transformações dessas vêm ocorrendo e ganhando cada vez mais visibilidade, convocando-nos a reexaminar as estruturas familiares, os sistemas simbólicos de parentesco, filiação e sexualidade.

No âmbito do familiar deparamo-nos com arranjos diversos na contemporaneidade - as famílias monoparentais por opção, pluriparentais, casais sem filhos por opção, a família homoparental, dentre outras. A homoparentalidade ${ }^{3}$ vem ganhando visibilidade e sinaliza um momento de experimentação e de construção de novas formas de ser e de se relacionar, trazendo à tona questões como a vivência de novos papéis e funções dentro do grupo familiar. $O$ desejo dos homossexuais de serem reconhecidos como casais e família, entendido por alguns estudiosos como um giro conservador e irreflexivo do movimento homossexual em direção à norma familiar (Vespucci, 2014), traz também uma nova ideia de família, o que resulta em intensos processos de negociação simbólica e em ressignificações (Roudinesco, 2003).

Para melhor entendermos a homoparentalidade, é preciso esclarecer o termo "parentalidade". Criado em detrimento dos termos "maternidade" e "paternidade", ele trouxe um avanço na forma de compreender as construções relacionais no contexto da família (Solis-Ponton, 2004), pois, destina-se à nomeação dos vínculos de parentesco e dos processos psicológicos que se desenvolvem a partir destes. É resultante da junção dos termos "paternalidade" e "maternalidade" (Solis-Ponton, 2004) e se diferencia dos termos "paternidade"

\footnotetext{
3 A família homoparental é aquela em que ao menos um indivíduo homossexual assume a responsabilidade por uma criança. Homoparentalidade é uma nomenclatura francesa, o termo foi criado em 1997, pela APGL [Associação de pais gays e lésbicas] (Roudinesco, 2003), e pode ser resultado de família recomposta com filhos de relacionamento heterossexual anterior, adoção ou o uso de tecnologias reprodutivas.
} 
e "maternidade", uma vez que busca romper com o modelo tradicional de família, retirando a ênfase no vínculo biológico existente entre o pai, a mãe e os filhos e enfatizando a dimensão psíquica desse vínculo.

A parentalidade se vincula à parentalização, a qual envolve questões geracionais e reativas nos pais, sendo construída a partir de processos complexos, como o contrato narcísico por exemplo. Tornar-se pai ou mãe implica um trabalho interior que começa pela aceitação de que herdamos algo de nossos pais e do qual podemos nos tornar meros repetidores ou autores de um novo legado.

$\mathrm{Na}$ contemporaneidade a parentalidade vem sendo elaborada de forma diferenciada, marcada por relações mais flexíveis e dialogadas de gênero. Nessas relações, a função de cuidar está mais relacionada à subjetividade individual do que à sexualidade ou ao gênero (Santos, 2004).

A composição das novas famílias diante do ideário da família tradicional levanta questões sobre a noção de família e as categorias a ela relacionadas funções e papéis, gênero e sexualidade. Partindo deste ponto, pretendemos realizar uma reflexão acerca das formas de nomeação dentro da família, mais especificamente no que diz respeito à parentalidade, à função materna e à função paterna, para além da norma binária de gênero.

A dificuldade de nomeação das novas formas de família está relacionada com o estranhamento que aquilo que é novo causa (Berenstein, 2007), podendo se vincular a um preconceito. Esse estranhamento está associado com aquilo que não pode ser representado (Zambrano, 2008) e se refere a um irrepresentável, com o qual os sujeitos encontram dificuldade de lidar. O irrepresentável não é o mesmo que o diferente, pois este último pode sim ser representado e nomeado, sendo compreendido como parte da realidade.

A família tradicional, conforme concebida pela teoria psicanalítica desde o seu nascimento com Freud no final do século XIX, pressupõe descrições de parentesco, funções e papéis que ordenam o funcionamento do grupo. Essas descrições supostamente estáveis serão questionadas neste artigo com o objetivo de desconstruir a ideia de lugares clássicos de parentesco, tais como os tradicionais papéis materno, paterno e o lugar ocupado pelo filho (Berenstein, 2007). Na contemporaneidade, esses lugares estão sendo experimentados com um pouco mais de fluidez. Nesse sentido, o intuito de discorrer acerca dessas funções e suas nomeações rigidamente estipuladas e mantidas é o de ampliar a discussão e trazer elementos reflexivos a fim de questionar e de exercitar novas possibilidades de realidade e de pensamento.

A concepção de um modelo tradicional da família, de configuração heterossexual, monogâmica e nuclear, considerado como invariável, inequívoco e natural, desconsidera sua dimensão histórica e socioconstruída (Moscheta \& Santos, 2009), dificultando e até impossibilitando a compreensão de outros formatos de família e de diferentes formas de se exercer as funções parentais. 
A psicanálise pode ser considerada um saber epistêmico e ético que regula e orienta a sociedade acerca do que vem a ser saudável e aceitável no horizonte humano, num determinado período histórico. Reconhecida como uma espécie de guardiã da ordem simbólica e também como produtora de formas de subjetivação (Levy, 2011), é preciso que esta faça constantemente uma crítica de si mesma com o objetivo de evitar se tornar uma prática que ratifica e naturaliza a ordem sexual e familiar.

No começo da década de 1920, Freud (1923/1976) apresentou à sociedade o modelo do Complexo de Édipo, acompanhado de teorizações a respeito dos lugares e papéis paternos e maternos. Tais teorizações do romance familiar e do complexo de Édipo, acopladas à cultura da época, vão sofrendo transformações e/ou ampliações para se adaptarem à realidade dos arranjos familiares da contemporaneidade. Os modelos psicanalíticos delineados por Freud, com suas noções de ordem simbólica e familiar, buscando indicar os ideais de subjetivação, acabavam reproduzindo uma perspectiva heterocêntrica.

Segundo essa perspectiva teórica e social, as funções habitualmente atribuídas ao lugar da Mãe se referem aos seguintes cuidados: assistir o filho material e emocionalmente, auxiliando na condição de desamparo inicial do bebê, bem como durante todo o seu desenvolvimento, além de dar um lugar ao pai, abrindo espaço para a presença do outro. O lugar do Pai concerne prioritariamente à tarefa de proibir: obstaculizar a aproximação excessiva do filho com a mãe, indicar as diferenças de lugares e funções dentro da família e transmitir as vozes do sociocultural (Berenstein, 2007). Sabemos que apesar de considerados naturais esses papéis são construções sociais (Puget, 2015; Berenstein, 2007; Derrida \& Roudinesco, 2004). Tal como afirmou Badinter (1986), há mais de trinta anos, a linha que separa os campos da maternidade e da paternidade tem se apagado. Desde então, os homens têm passado a desempenhar papéis que ainda hoje são considerados como próprios ao universo feminino: seja no cuidado com os filhos, na divisão das tarefas domésticas ou no exercício profissional.

Em 2013, foi proposto um projeto de lei na França para substituir os termos "mãe" (mère) e "pai" (père) pelo termo "pais" (parents) o qual foi entendido como "perverso devido à considerada recusa da Lei e da diferença sexual, ao seu furor destrutivo da linguagem e à sua onipotência" (Ayouch, 2015, p. 26).

Com a homoparentalidade, os lugares atribuídos à masculinidade e feminilidade, à mãe e ao pai e ao cruzamento entre gênero e sexualidade devem ser colocados em outros termos com vistas a um processo de transformação das representações sociais (que remetem à heteronormatividade) para que, assim, possamos pensar uma nova ordem simbólica: aberta para o novo, para o diferente. Cabe citar aqui que os argumentos mais utilizados contra a homoparentalidade se referem à necessidade de preservação da instituição 
família, em defesa da ordem familiar como condição da cultura e lugar de emergência da subjetividade (Arán, 2011). Não é incomum que a resistência ao reconhecimento de outras formas de família e de parentesco, sustentada pelos referenciais da psicanálise intrapsíquica, se fixe na relevância da manutenção da diferença sexual como condição necessária para o processo de subjetivação.

Conceber uma nova ordem simbólica implicaria compreender o fenômeno de desestabilização das relações entre sexo e gênero, no qual a lógica da norma binária (masculino/feminino, heterossexual/homossexual) é desnaturalizada. 0 gênero é o mecanismo pelo qual as noções de masculino e de feminino são produzidas e normalizadas (Butler, 2004), e dentro de uma concepção binária e heteronormativa, somente uma mulher poderia exercer a chamada função de mãe, e um homem a função de pai.

Para ilustrar a questão da dificuldade de nomeação do novo nas famílias contemporâneas, escolhemos trazer um caso de uma família homoparental composta por dois homens e seus dois filhos adotivos residentes na cidade de São Paulo4. O material relatado faz parte de uma pesquisa de Doutorado realizada com um total de cinco famílias (segundo as características amostrais mencionadas acima), de metodologia clínico-qualitativa, utilizando-se de entrevistas semidirigidas e genogramas. Justificamos tal escolha devido ao fato de que esse é um dos arranjos que mais têm causado impacto e preconceito tanto no âmbito psicanalítico quanto na sociedade em geral. Diversos autores do meio psicanalítico (Melman, 2003; Legendre, 2004; Schneider, 2006; Winter, 2010) têm se posicionado negativamente diante da homoparentalidade, discorrendo teoricamente acerca das confusões e dos prejuízos que podem ser gerados em decorrência de uma configuração homoparental de família.

\section{A FAMÍLIA DE ANTÔNIO E NORI}

A família é composta pelo casal Antônio e Nori, e seus dois filhos Vicente e Julia $^{5}$. O casal está junto há mais de dez anos e constitui uma relação estável. Ambos relatam que não houve um momento de assunção das homossexualidades, pois acreditam ser desnecessário alguém se assumir enquanto um sujeito homossexual, haja vista que os heterossexuais não são convocados a tal posicionamento. Nori saiu da casa de sua família para viver com Antônio. Este parece ter sido o momento em que ele assumiu para sua família sua homossexualidade. Após um período de dez anos, o casal começou a pensar na possibilidade de ampliar a família e de ter filhos, mediante adoção.

\footnotetext{
4 Segundo o Censo de 2010, há no Brasil mais de 60 mil casais homossexuais vivendo juntos, o que aponta para a existência de um número considerável de famílias homoparentais (Lauriano \& Duarte, 2011).

5 Todos os nomes são fictícios a fim de preservar as identidades dos sujeitos.
} 
O casal foi entrevistado um ano após a adoção dos irmãos, na época com cinco e dois anos de idade (respectivamente). O casal relatou ter passado por um considerável período de preparação (três anos) para efetivar o pedido de adoção, organizando-se financeira e psiquicamente para a chegada dos filhos: o que incluiu a mudança de casa, de carro e o abandono de hábitos como fumar.

Eles contaram que logo que receberam as crianças em casa (ainda em guarda provisória) ficaram em dúvida quanto à nomeação que proporiam para os filhos. A falta de referência, a ausência de modelos familiares como os deles, fez com que se sentissem desamparados e confusos, questionando até mesmo suas habilidades para cuidar e criar as crianças, uma vez que seus papéis não se encontravam legitimados socialmente.

$\mathrm{Na}$ concepção de Butler (1990) as categorias "homem" e "mulher" só alcançam estabilidade e coerência no contexto da matriz heterossexual. Esta matriz, por sua vez, sustenta a crença numa relação mimética entre sexo e gênero (na qual o último reflete o primeiro) dentro de um sistema binário de gêneros: o masculino e o feminino. Propor a realidade de um homem que exerça a maternidade seria, portanto, um contrassenso diante da concepção binária de gêneros. Desse modo, é preciso alterar o sistema de nomeação das estruturas familiares (de parentesco e de filiação) a fim de que se permita pensar a possibilidade de pais-mulheres e mães-homens, por exemplo.

É por meio desse sistema binário hierárquico que o gênero é materializado nos corpos por normas regulatórias constantemente reiteradas, repetidas e ratificadas e que assumem o caráter de normalidade (Butler, 1990). Tudo isso ocorre em um processo que visa disciplinar formas de masculinidades e de feminilidades possíveis e diferentes entre si (Petry \& Meyer, 2011). É preciso pensar a historicidade dessa relação entre o masculino e o feminino, admitindo o conflito constitutivo dessa oposição para que possamos refletir sobre a alteridade, premissa para a constituição subjetiva de qualquer ser humano (Arán, 2009).

Para Butler (2004), a norma cria uma condição de inteligibilidade, ou seja, humaniza aquilo que está sob seu regime. Aquilo que escapa à norma, que não cabe dentro dela, torna-se ininteligível. O ininteligível é abjeto e, como tal, tem negadas suas possibilidades de existência. Nesse sentido, não dispor socialmente de um nome com o qual se possa diferenciar dois homens que criam dois filhos é um ato a partir do qual esse exercício específico da parentalidade é colocado num lugar de impossibilidade, de não existência, de aberração. As possibilidades de resistência e de transgressão da norma heterocêntrica ocorrem justamente no campo das relações cotidianas, nos cenários que examinamos no decorrer do estudo com essas famílias homoparentais.

No caso de Antônio e Nori, ao adotar, ambos decidiram que gostariam de ser chamados de "papai". Assim ensinaram aos dois filhos, o que foi aceito num primeiro momento. A vontade desses dois homens de serem chamados de 
"papai" estava relacionada ao desejo de ocupar o lugar de "Pai" e de, com isso, poder se posicionar e atuar enquanto pais. Isto não excluía, todavia, a possibilidade de exercer funções tradicionalmente vinculadas ao papel materno.

Ao vincular às mulheres o papel de mãe e aos homens o papel de pai, tomamos o gênero como um efeito de verdade produzido nas superfícies dos corpos e construído como uma ficção reguladora: capaz de determinar que configurações culturais de gênero irão assumir o lugar de "reais" (consideradas possíveis e legítimas) em detrimento daquelas que irão ocupar o território da irrealidade, da impossibilidade, da invisibilidade social (Butler, 2004). O casal de homens entrevistado se deparou com essa irrealidade: a do inominável - o fato de seus lugares como pais/cuidadores não ter nome - e se dispôs a construir um lugar real, possível e legítimo por meio do fenômeno vincular. Se inicialmente eles escolheram se apresentar aos filhos como: "papai e papai", diante do incômodo manifesto por uma das crianças, aceitaram o modo como o filho inventou outra denominação. O estranhamento diante do irrepresentável da homoparentalidade culminou com a dificuldade desse casal de encontrar uma saída criativa para lidar com o diferente, com a nomeação de duas pessoas responsáveis pelos filhos que compartilhavam o mesmo sexo e o mesmo gênero.

A questão conflituosa foi resolvida pelo filho Vicente. A ele coube se posicionar diante do incômodo com a confusão de ter dois pais e não saber como diferenciá-los com palavras. Como enfatizou Benghozi (2010), atualmente são as crianças que "fazem famílias", destacando a importância de um processo de adoção dos filhos pelos pais e dos pais pelos filhos. Vicente, de forma espontânea, sugeriu chamar o pai que passava mais tempo em casa de "papia" e o pai que trabalhava fora de casa de "papai". A escolha dos termos, intuitiva e inteligente, mesmo em se tratando de uma criança pequena e com vocabulário restrito, denota a compreensão da importância de uma nomeação clara e inequívoca para duas pessoas diferentes, para além de seus sexos e gêneros (dois homens, ambos masculinos).

A dificuldade na desvinculação entre sexo e gênero pode ser percebida nesse casal parental, por exemplo, quando relacionaram o cuidado com os filhos como algo específico do universo feminino (Freud, 1930/2010). O casal compartilhou a ideia de que Ihes faltaria algo exclusivo das mulheres no cuidado com os filhos e daí decorreria a dificuldade em atentar aos detalhes, como a necessidade de sempre carregar uma troca de roupa para as crianças. Reforçando as representações sociais marcadas pelo sistema binário de gênero (Butler, 1990), eles alegaram que estariam se aproximando de um lado mais feminino de seu ser para exercer a parentalidade, ainda vista prioritariamente como um cuidado materno (Badinter, 1985).

Chodorow (1990) reconheceu o processo da maternação como decisivo na organização dos gêneros e abriu uma perspectiva de mudança por intermédio da ideia de "reprodução da maternação" desvinculada de seu imperativo exercício 
feminino. Concordamos com sua crença na possibilidade de um exercício da maternação realizado também por homens, o que geraria um efeito significativo na sociedade, no sentido da diluição das fronteiras entre os gêneros.

A dificuldade do casal para encontrar uma nomeação para eles próprios com a chegada dos filhos se deveu à ausência de legitimidade que há nesse lugar de pai no contexto da família homoparental. Apesar da conquista da adoção legal conjunta, permanece o estranhamento por parte dos protagonistas acerca da história que estão construindo. A questão central desse casal é a mesma de muitos sujeitos homossexuais e de suas famílias, uma vez que eles se deparam com o que Butler (2002/2003) chama de "lugar não cooptado pela normatividade", lugares de não representatividade e, então, são obrigados a criar nomes, a construir lugares nunca antes habitados. Essas novas nomeações ainda não legitimadas no meio social, dependem da aceitação e do reconhecimento do outro para que se tornem reais.

A experiência da família de Antônio e Nori aponta que a parentalidade exclusivamente masculina é afetada pela falta de modelos referenciais, na medida em que o legado familiar desse casal (e de muitos outros) ainda se encontra preso ao modelo heterossexual, o que leva esses homens muitas vezes a se sentirem inseguros e despreparados para as tarefas vistas até então como "maternas".

As novas configurações familiares contemporâneas atravessam transformações nos sistemas de nomeação, filiação e nas relações de gênero. Isto permite que o modelo familiar tradicional (heterocêntrico) seja posto em questão. Assim, surgem brechas como as novas possibilidades de nomeação e os espaços de transição que questionam os rígidos demarcadores da masculinidade e da feminilidade. Para se pensar sobre a possibilidade de surgimento de uma nova ordem simbólica, no entanto, é primordial compreender o acontecimento da desestabilização das relações entre sexo e gênero, masculino e feminino, homossexual e heterossexual, ou seja, em maior grau refletir sobre a desnaturalização da própria lógica binária com a qual fomos acostumados a organizar o mundo (Corbett, 2009; Bourdieu, 2005).

\section{CONSIDERAÇÕES FINAIS}

Da mesma maneira como Butler (1990) busca desconstruir e desnaturalizar as concepções e relações entre gênero e sexo, é preciso repensar os lugares de parentesco na família. Já não podemos falar da Família como uma instituição com lugares e funções pré-estabelecidas: a mãe que cuida, o pai que regula, exerce a autoridade e garante a lei simbólica. É preciso pensar a família como uma organização filiativa que permite a construção de lugares de cuidado e de inserção cultural. Há na contemporaneidade uma nova forma de conceber família que vem sendo construída no ser-fazer (Puget, 2015) do dia a dia. Tal 
forma questiona e desmonta os modelos normativos pautados nas representações sociais rigidamente ancoradas nos lugares e funções específicos da mãe separados dos lugares e funções específicos do pai. Ao nos depararmos com uma família na qual os cuidadores não se encaixam nos estatutos normativos, como os nomeamos?

É preciso haver uma nomeação comum para todas as famílias? Seria possível considerar os dois homens da família apresentada como dois pais? Levando-se em conta a definição do que é ser pai, teríamos então que afirmar que eles assumem o papel materno também? Como entender que, para além de serem dois homens, eles assumem funções não apenas de "pai" - como é tipicamente compreendido - mas também de "mãe"? Ou pensando de forma mais ampla: como apreender e nomear o fato deles terem adquirido a habilidade de circular entre os dois papéis?

Se as categorias de "homem" e "mulher" só alcançam estabilidade e coerência no contexto da lógica heteronormativa, podemos pensar que as famílias homoparentais - ao conceber e colocar em prática funcionamentos familiares igualitários e criativos (nos quais a norma heterocêntrica não precise ser o imperativo) - trariam a possibilidade da existência de pais-mulheres ou de mães-homens, por exemplo. Ou, mais ainda, legitimariam a existência de sujeitos que são cuidadores e que podem partilhar essa função com outra pessoa (quando formam um casal), mas que não precisam se ajustar a estereótipos rígidos de gênero para serem reconhecidos socialmente como pessoas capazes de criar seus filhos.

Derrida \& Roudinesco (2004) apontaram para a urgência na consideração da mutação da relação entre pai e mãe, funções materna e paterna, haja vista que todas as relações estariam se modificando com o surgimento das novas famílias. Diante das possibilidades de mobilidade de lugares dentro da configuração familiar, os autores enfatizaram que a família nunca foi natural para nenhum ser vivo, e nos colocaram diante de algumas questões: "Será que um casal de homens homossexuais impõe dois pais masculinos para o(s) filho(s)"? De alguma maneira, existiriam sempre, em todas as situações, o que chamamos correntemente de "um pai" e "uma mãe"? (p. 50).

Ayouch (2015), numa publicação atual, convoca-nos a questionar os operadores simbólicos: homem, mulher, mãe, pai. Seriam esses termos significantes atemporais da subjetivação, ou apenas ferramentas que carregam um sentido cultural e uma inflação imaginária decorrente de sua inscrição histórica? Sendo assim, como "desimaginarizá-los"?

A psicanálise vincular em especial tem ampliado as conceituações teóricas enfatizando o indivíduo que se constitui no vínculo com outro, englobando o legado geracional e o social mais amplo. Num processo de ampliação e de inovação do pensamento, é fundamental desinstitucionalizar o discurso 
dogmático e conservador que insiste em se recusar a ver e compreender as novas formas de fazer e de viver em família.

Desse modo estaríamos desautorizando o normativo familiar na medida em que ampliamos, para alem de Freud e Lacan, a releitura do Complexo de Édipo e a retirada da ênfase sobre a diferença sexual e sua consequente lógica binária como fundante da subjetivação. Ao invés da binariedade de posições de sexuação (Knudsen, 2007) sugerimos a inclusão de uma visão múltipla e a consideração da alteridade como condição subjetivante na contemporaneidade. Nesse sentido, concordamos com Áran (2009) no que concerne à necessidade da psicanálise se abrir cada vez mais para a leitura de outras sexualidades que não estão restritas ao masculino e ao feminino enquanto as duas únicas posições normativas.

Retomamos o questionamento de Tort (2001), após quinze anos transcorridos - "Que contribuição pode dar a psicanálise à compreensão desse novo dispositivo que determina as identificações, através de um agenciamento inédito das funções maternas e paternas?" (p. 12), para demonstrar o desafio permanente da psicanálise no sentido de refletir, dialogar e teorizar sobre as transformações sociais e seus impactos subjetivos.

Como demonstrado pelo casal da pesquisa, ao se deparar com uma realidade inominável até então, com o vácuo decorrente da ausência de um lugar socialmente legitimado para dois homens que criam seus filhos, o vínculo tecido na família possibilitou a invenção de nomes e de funções singulares para cada um dos pais. Houve um trabalho psíquico tecido no vínculo que permitiu uma apropriação dos legados geracionais herdados e a construção de uma nova lógica possível (não mais fundada na heteronormatividade e na binariedade), capaz de reger o funcionamento do grupo familiar. Essa invenção construída pela dinâmica vincular nos faz perceber que se existe um risco de indiferenciação numa família homoparental este não resulta do laço homoafetivo em si, mas sim de uma recusa social em reconhecer esse modelo familiar e, desse modo, instituir papéis e/ou funções sociais distintos para cada um dos pais (Parseval, 2008).

Cabe à psicanálise investigar os agenciamentos singulares criados pelas novas famílias e pensar em que medida eles se colocam como estratégias de resistência e como possibilidades de enfrentamento e de recriação daquilo que, no modelo freudiano de subjetivação, não escapou à heteronormatividade.

Observamos na atualidade um movimento da produção psicanalítica no sentido de reconhecer a pluralidade de novas formas de ser e de se vincular exibidas pelas novas famílias, o que leva a uma reavaliação crítica de seus conceitos, já mencionados anteriormente (Ayouch, 2015). Por exemplo, quando autores (Arán, 2009; Duchene, 2012) propõem que a alteridade com a qual a criança se depara ao atravessar o Édipo não precisa necessariamente remeter à dualidade sexual, mas, fundamentalmente, à singularidade psíquica dos sujeitos. 
Puget (2015) aponta os "efeitos do presente", daquilo que se faz no agora, indicando que as novas famílias impelem à criação de novas representações que, por sua vez, possam dar conta das novas realidades sociais. No ser-fazer cotidiano, elas estão inventando para si novos lugares e nomeações que escapam e subvertem a norma heterocêntrica. Ao ouvir essas famílias e suas narrativas, a psicanálise tem a possibilidade de ela própria se reinventar, considerando que é filha de uma cultura e, enquanto tal, deve contribuir para que os cidadãos que dela fazem parte tenham ampliadas suas possibilidades de existência.

\section{REFERÊNCIAS}

Almeida, M. R. (2012). Os processos subjetivos no acolhimento e na adoção de crianças por casal homoafetivo: um estudo de caso. Tese de Doutorado, Instituto de Psicologia, Universidade de São Paulo. São Paulo.

Amazonas, M. C. L. A., \& Braga, M. G. R. (2006, jul/dez). Reflexões acerca das novas formas de parentalidade e suas possíveis vicissitudes culturais e subjetivas. Ágora, 9(2), 177-191, doi: 10.1590/S151614982006000200002. Recuperado em 23 de novembro de 2016, de http://www.scielo.br/pdf/agora/v9n2/a02v9n2.pdf.

Arán, M. (2003, julho/dezembro). Os destinos da diferença sexual na cultura contemporânea. Revista Estudos feministas, 11(2), 399-422.

Arán, M. (2009, setembro/dezembro). A psicanálise e o dispositivo da diferença sexual. Revista Estudos Feministas, 17(3), 653-673.

Arán, M. (2011). Políticas do desejo na atualidade: a psicanálise e a homoparentalidade. Revista Psicologia Política, 11(21), 59-72.

Ayouch, T. (2015). Psicanálise e Homossexualidades: Teoria, clínica, biopolítica. Curitiba, SC: CRV.

Badinter, E. (1985). Um amor conquistado: o mito do amor materno. Rio de Janeiro, RJ: Editora Nova Fronteira.

Badinter, E. (1986). Um é o outro. Rio de Janeiro: Nova Fronteira.

Benghozi, P. (2010). Malhagem, Filiação e Afiliação. Psicanálise dos vínculos: casal, família, grupo, instituição e campo social. (E. D. Galery, trad.). São Paulo, SP: Vetor.

Berenstein, I. (2007). Del ser al hacer: Curso sobre vincularidad. Buenos Aires, Argentina, Barcelona, Espanha, México: Paidós.

Borges, C. C., \& Coutinho, M. L. R. (2008). Família e Relações intergeracionais no Brasil hoje: Novas configurações, crises, conflitos e ambiguidades. In Gomes I. C. (Coord.) Família: diagnóstico e abordagens terapéuticas (pp. 45-59). Rio de Janeiro, RJ: Guanabara Koogan.

Bourdieu, P. (2005). A dominação masculina. (4a ed., M. H. Kuhner, trad.). Rio de Janeiro, RJ: Bertrand Brasil. 
Butler, J. (1990). Problemas de gênero: Feminismo e subversão da identidade. Rio de Janeiro, RJ: Civilização Brasileira.

Butler, J. P. (2003). O parentesco é sempre tido como heterossexual? (V. A. da Ponte, trad., P. Dentzien, rev. tec.). Cadernos Pagu, 21, 219-260. (Trabalho original publicado em 2002).

Butler, J. P. (2004). Undoing gender. New York, EUA: Routledge.

Câmara dos Deputados (2014). Enquete: Você concorda com a definição de família a partir da união entre homem e mulher, prevista no projeto que cria o Estatuto da Família?. Brasília, DF: Autor. Recuperado em 06 de fevereiro de 2016, de http://www2.camara.leg.br/enquetes/votarEnquete/enquete/101CE64E8EC3-436C-BB4A-457EBC94DF4E.

Chodorow, N. (1990). Psicanálise da maternidade. Rio de Janeiro, RJ: Rosa dos tempos.

Corbett, K. (2009). O mistério da homossexualidade. Jornal de Psicanálise, 42(76), 159-176.

Derrida, J., \& Roudinesco, E. (2004). De que amanhã: Diálogo. Rio de Janeiro, RJ: Jorge Zahar.

Dicionário Houaiss vai alterar definição do termo família (2016, 13 de abril) 0 Globo online. Recuperando em 20 de abril de 2016, de http://oglobo.globo.com/sociedade/dicionario-houaiss-vai-alterar-definicaodo-termo-familia-19074406.

Duchenne, S. (2012). Je ne sais pas ce que je serais sans "nanou". Reflexion autor de l'adoption par les couples d'homosexuelles. La revue Lacanienne, 135-143.

Eiguer, A. (2010). Homoparentalidades, afiliación y vínculo filial. In Rotenberg, E., \& Wainer, B. A. (Orgs.). Homoparentalidades: Nuevas familias (2a edic., pp.127-137). Buenos Aires, Argentina: Lugar Editorial.

Freud, S. (1976). O id e o ego. In Edição standard das obras psicológicas completas de Sigmund Freud (J. Salomão, trad., Vol. 19, pp. 13-83). Rio de Janeiro, RJ: Imago. (Trabalho original publicado em 1923).

Freud, S. (2010). O mal estar na civilização, novas conferências introdutórias à psicanálise e outros textos. In Obras completas de Freud: Psicologia analítica (Vol. 18). São Paulo, SP: Companhia das letras. (Trabalho Original publicado em 1930).

Horkheimer, M. (2003). Autoridade e família. In Horkheimer, M. Teoria Crítica I (pp. 76-150). Buenos Aires, Argentina: Amorrortu.

Käes, R. (2011). Um singular plural: A Psicanálise à prova do grupo. São Paulo, SP: Edições Loyola Jesuítas.

Knudsen, P. P. P. S. (2007). Gênero, Psicanálise e Judith Butler - Do transexualismo à política. Tese de Doutorado, Instituto de Psicologia, Universidade de São Paulo, São Paulo. 
Lauriano, C., \& Duarte, N. (2011, 29 de abril). Censo 2010 contabiliza mais de 60 mil casais homossexuais. G1. Recuperado em 28 de julho de 2016, de http://glo.bo/mzwP9X.

Legendre, P. (2004). Poder genealógico do Estado. In Altoé, S. (Org.) Sujeito do direito, sujeito do desejo: Direito e psicanálise (pp.79-87). Rio de Janeiro, RJ: Revinter.

Levy, L. (2011). A psicanálise e a homoparentalidade. Cadernos de Psicanálise, 27(30), 153-176.

Melman, C. (2003). O homem sem gravidade: Gozar a qualquer preço. Rio de Janeiro, RJ: Cia de Freud.

Moscheta, M. S., \& Santos, M. A. (2009). Relação conjugal homoafetiva: Revolução ou acomodação? In Cunha, M. V., Pasian, S. R., \& Romanelli, G. (Orgs). Pesquisas em Psicologia: Múltiplas abordagens (pp. 129-152). São Paulo, SP: Vetor.

Parseval, G. D. (2008). Famille à tout prix. Paris: Éditions du Seuil.

Petry, A. R., \& Meyer, D. E. E. (2011). Transexualidade e heteronormatividade: Algumas questões para a pesquisa. Revista Textos e Contextos, 10(1), 193198.

Puget, J. (2015). Subjetivación discontinua y psicoanálisis. Incertidumbres y certezas. Buenos Aires, Argentina: Lugar editorial.

Puget, J., \& Berenstein, I. (1993). Psicanálise do casal. Porto Alegre, RS: Artes médicas.

Rios, M. G. (2007). Casais em filhos por opção, análise psicanalítica através de entrevistas e TAT. Dissertação de Mestrado, Instituto de Psicologia, Universidade de São Paulo, São Paulo.

Roudinesco, E. (2003). A família em desordem. Rio de Janeiro, RJ: Jorge Zahar.

Santos, C. (2004). A parentalidade em famílias homossexuais com filhos: Um estudo fenomenológico de vivências de gays e lésbicas.Tese de Doutorado,Faculdade de Filosofia, Ciências e Letras de Ribeirão Preto, Universidade de São Paulo, Ribeirão Preto, SP.

Schneider, M. (2006) Surimpressions sexuelles. Cliniques mediterranées, 74(2), 27-42.

Solis-Ponton, L. (Org.) (2004). Ser pai, ser mãe: Parentalidade: Um desafio para o Terceiro Milênio (M. C. P, Silva, rev. tec. trad.). São Paulo, SP: Casa do Psicólogo.

Spivacow, M. A. (2012). Clínica psicoanalitica con parejas: Entre la teoria y la intervencion. Buenos Aires, Argentina: Lugar Editorial.

Tort, M. (2001). O desejo frio: Procriação artificial e a crise dos referenciais simbólicos. Rio de Janeiro, RJ: Civilização Brasileira.

Uziel, A. P. (2007). Homossexualidade e adoção. Rio de Janeiro, RJ: Garamond. 
Vespucci, G. (2014). Una fórmula deseable: El discurso "somos famílias" como símbolo hegemônico de las reivindicaciones gay-lésbicas. Revista Latinoamericana: Sexualidad, Salud y Sociedade, 17, 30-35.

Zambrano, E. (2008). "Nós também somos família": Estudo sobre a parentalidade homossexual,travesti e transsexual. Tese de Doutorado, Instituto de Filosofia e Ciências Humanas, Universidade Federal do Rio Grande do Sul, Porto Alegre.

Winter, J. P. (2010). Homoparentalité et refus du réel. Études, 412(5), 607-615.

Sobre os autores

Brunella Carla Rodriguez é psicóloga graduada pela Universidade Presbiteriana Mackenzie (2008), Mestre em Psicologia Clínica pela Universidade de São Paulo (2012), doutoranda em Psicologia Clínica pela Universidade de São Paulo. brunellarodriguez@usp.br

Isabel Cristina Gomes é psicóloga graduada pela Universidade de São Paulo (1980), mestrado em Psicologia Social pela Universidade de São Paulo (1990) e doutorado em Psicologia Social pela Universidade de São Paulo (1996), Professora Titular do Instituto de Psicologia da Universidade de São Paulo e Coordenadora do Laboratório de Casal e Família: Clínica e Estudos Psicossociais. isagomes.usp@gmail.com

Danielly Passos de Oliveira é psicóloga graduada pela Universidade Federal (2000), mestrado em Letras pela Universidade Federal do Ceará (2003) e doutorado em Sociologia pela Universidade Federal do Ceará e pela Université Paris VII (2008). daniellypassos@yahoo.com.br

Recebido em: 10/05/2016 Revisado em: 21/11/2016

Aceito em: 13/12/2016 